\title{
REMUNERAÇÃO SALARIAL DE PROFESSORES EM REDES PÚBLICAS DE ENSINO'
}

Maria Dilnéia Espíndola Fernandes*

Solange Jarcem Fernandes**

RESUMO: O trabalho analisa a remuneração salarial de professores das redes de ensino estadual e municipal na cidade de Campo Grande, capital do estado de Mato Grosso do Sul, no período de 1998 a 2010, durante a vigência do Fundef e nos quatro primeiros anos de implementação do Fundeb. Trabalhou-se com a legislação nacional, estadual e municipal, indicadores educacionais do Instituto de Estudos e Pesquisas Educacionais "Anísio Teixeira", documentos das secretarias estadual e municipal de educação, balanços gerais de contas de governos e as tabelas salariais oficialmente divulgadas. Constatou-se que não houve impactos significativos em termos de ganhos e/ou aumentos na remuneração de professores, como, a princípio, pareceram indicar as políticas de fundos contábeis.

Palavras-chave: Política Educacional; Remuneração Salarial Docente; Financiamento para Manutenção e Desenvolvimento do Ensino; Fundos Contábeis.

\section{TEACHERS' REMUNERATION IN PUBLIC EDUCATION DISTRICTS}

ABSTRACT: The paper analyzes the remuneration of teachers working in state and local school districts in the city of Campo Grande, capital of the state of Mato Grosso do Sul, in the period from 1998 to 2010, during the effectiveness of Fundef and the first four years of its implementation. The study included national, state and municipal legislation, educational indicators from the Educational Studies and Research Institute "Anísio Teixeira", documents from state and municipal education secretariats, general government account balances, and salary tables officially disclosed. There were no significant impacts in terms of gains and/or increases in the remuneration of teachers as, at first, the fund accounting policies seemed to indicate.

Keywords: Educational Policy; Teachers' Remuneration; Funding for Education Maintenance and Development; Accounting Funds.

\footnotetext{
* Doutora em Educação pela Universidade Estadual de Campinas (UNICAMP); Professora Associada do Programa de PósGraduação em Educação da Universidade Federal do Mato Grosso do Sul (UFMS). E-mail: mdilneia@uol.com.br

* * Doutora em Educação pela Universidade Federal do Mato Grosso do Sul (UFMS); Professora da Rede Muncipal de Educação de Campo Grande/MS. E-mail: solangejarcem@yahoo.com.br
} 


\section{Introdução}

Este trabalho objetiva analisar o percurso da remuneração salarial de professores no período de 1998 a 2010, das redes de ensino estadual e municipal na cidade de Campo Grande, capital do estado de Mato Grosso do Sul. O recorte temporal é o da implantação do Fundo de Manutenção e Desenvolvimento do Ensino Fundamental e de Valorização do Magistério (Fundef) e dos quatro primeiros anos de execução do Fundo de Manutenção e Desenvolvimento da Educação Básica e de Valorização dos Profissionais da Educação (Fundeb).

A escolha das duas redes de ensino justifica-se pelo fato de que ambas detêm o maior contingente de professores atuando no estado de Mato Grosso do Sul, de forma que os dados analisados expressam a situação salarial de um grande contingente dessa categoria profissional em todo o estado.

Os dados que subsidiam este estudo provêm da legislação educacional de âmbitos federal, estadual e municipal, de documentos das secretarias de Educação do estado e do município, do Instituto de Estudos e Pesquisas Educacionais "Anísio Teixeira" (INEP), dos Balanços Gerais do Estado de Mato Grosso do Sul, dos Balanços Consolidados do Município de Campo Grande, das tabelas sobre vencimento base salarial de professores publicadas no Diário Oficial do Estado de Mato Grosso do Sul (DIOSUL) e no Diário Oficial do Município de Campo Grande (DIOGRANDE).

De fato, no Brasil, a questão salarial do magistério ainda não está equacionada naquela dimensão de "[...] uma carreira condizente com a sua relevância social, com salários atraentes" (GATTI; BARRETO, 2009, p.239). Mesmo com a política de redistribuição de impostos entre estados e seus municípios e, quando necessário, com a complementação da União, imperativo operacionalizado a partir da promulgação das Leis $n^{\circ} 9.424 / 1996$ e no 11.494/2007 (BRASIL, 1996a, 2007a) e da Lei $\mathrm{n}^{\circ}$ 11.738/2008 (BRASIL, 2008a), que institui um Piso Salarial Profissional Nacional (PSPN), o impacto nos salários docentes, a partir dessas perspectivas jurídico-legais, remete ao seguinte cenário:

Há no país 5.561 municípios, 26 estados e um Distrito Federal, cada qual com seus sistemas de ensino e regulamentações próprias. A situação é bastante heterogênea e complexa nos aspectos referentes à carreira e salário 
dos professores, entre estados e entre municípios (conforme região, característica da população, sistema produtivo regional e local, capacidade financeira própria, repasses federais ou estaduais, tradições políticas e culturais etc.) (GATTI; BARRETO, 2009, p.237-238).

Em decorrência desse contexto, há que se considerar ainda que, em termos salariais, os vencimentos dos professores estão abaixo dos de outros profissionais com o mesmo grau e nível de formação, pois,

[...] os professores brasileiros ganham menos que outros profissionais do setor público do País, bem menos que seus colegas de outros países de renda per capita equivalente, possuem uma estrutura de carreira pouco estimulante a permanecer na profissão e constata-se uma grande discrepância salarial entre Estados da Federação e entre redes de ensino (PINTO, 2001, p.117).

Outro aspecto relevante, nesse cenário, é aquele ponderado por Gatti e Barreto (2009) sobre a atratividade na carreira:

[...] embora atualmente seja comum, em certos meios, o discurso que aumento de salário não garante maior qualidade, é preciso lembrar que carreiras pouco atraentes do ponto de vista salarial acabam por não ser objeto de procura entre as novas gerações, e especialmente não se mostram atraentes para aqueles que se consideram em melhores condições de domínio de conhecimentos, ou com melhores chances em outras atividades (GATTI; BARRETO, 2009, p.239-240).

Para Saviani, em entrevista publicada no informativo Expressão Sindical do Sinpro/Guarulhos, tais pontos são fundamentais, pois:

Sem encarar frontalmente o problema do magistério nenhuma reforma educacional terá chances de êxito. Trata-se de criar a carreira do magistério da educação básica tendo como itens básicos um piso salarial substantivamente elevado em relação ao atual e jornada em tempo integral numa única escola, com 50\% do tempo dedicado à docência e a outra metade distribuída pelas demais atividades. Quanto à formação, deve ser provida por meio de cursos presenciais regulares e de longa duração, ministrados por universidades que encarem a pesquisa sobre o magistério e a formação docente como prioridade. Os dois aspectos, carreira e formação, estão interligados (SAVIANI, 2007, p.2). 
De fato, a situação tratada por esses autores permitiria as condições materiais de existência do professor como força de trabalho, o que deveria expressar-se em termos salariais.

A situação salarial dos professores, no estado de Mato Grosso do Sul e no município de Campo Grande, materializa-se nesse panorama. A propósito, em pesquisa de âmbito nacional realizada pelo Sindicato dos Professores e Servidores do Estado do Ceará (SINDICATO dos Professores e Servidores do Estado do Ceará - Sindicato Apeoc, 2010), sobre o salário de professores iniciantes na carreira, a rede estadual de ensino de Mato Grosso do Sul ocupava o $10^{\circ}$ lugar no ranking divulgado pela entidade. Isso significa que o professor dessa rede de ensino, além de ganhar menos que outros profissionais com o mesmo grau e nível de formação, também tem os seus vencimentos diminuídos em relação à sua categoria profissional, quando comparados com os salários de outras redes públicas de ensino do país.

A categoria laboral do magistério do estado de Mato Grosso do Sul e do município de Campo Grande enfrentou, nos anos 1980, uma política de arrocho salarial em razão das opções políticas oriundas de suas administrações, pois a prioridade dessas gestões se concentrou nos investimentos de grandes obras públicas, em detrimento das políticas sociais (FERNANDES, 2001). Tal fato se expressou na política educacional em curso nos anos seguintes, quando se aprofundaram os impactos das decisões políticas dos anos 1980.

Assim, durante os anos 1990, a política educacional, no estado de Mato Grosso do Sul, “[...] expressou baixo nível de instrução da população, alta taxa de analfabetismo, insuficiência de escolas, número elevado de repetências e evasão escolar e o corpo docente com formação precária" (SENNA, 2000, p.18).

Nessa conjuntura, a valorização da carreira do magistério continua na agenda da política educacional, seja em resoluções congressuais da categoria representada pela Federação dos Trabalhadores em Educação de Mato Grosso do Sul (FETEMS) (RODRIGUEZ; FERNANDES, 2012), seja no escopo jurídico-legal, desde a promulgação da Constituição Federal de 1988 (BRASIL, 1988), que definiu o tema como um dos princípios basilares do ensino e previu planos de cargos, carreira e remuneração para o magistério público (PCCR). A propósito, a Lei $\mathrm{n}^{\circ}$ 9.424/1996 (BRASIL, 1996a) apresentou a exigência de que, 
em seis meses, a contar da data da sua promulgação, os entes da federação deveriam dispor de novos planos de PCCR.

$\mathrm{Na}$ rede estadual de ensino do estado de Mato Grosso do Sul, as modificações na legislação para a atualização do PCCR só ocorreram em 2000, dois anos após a implantação do Fundef. Até o ano 2000, a carreira da categoria esteve regida pelo Estatuto do Magistério, instituído pela Lei Complementar no 35/1988 (MATO GROSSO DO SUL, 1988). Em 2000, por meio da Lei Complementar no 87 (MATO GROSSO DO SUL, 2000a), o Estatuto do Magistério foi reformulado e vigora até a presente data.

Em Campo Grande, a Lei Complementar n ${ }^{\circ}$ 19/1998 (CAMPO GRANDE, 1998a) estabeleceu o Plano de Carreira e Remuneração do Magistério Público da Prefeitura Municipal de Campo Grande (PCRM).

Assim, na rede estadual de ensino, o magistério é caracterizado por profissionais da educação básica, tais como: servidores do grupo educação, que exercem atividades docentes, coordenação pedagógica, direção escolar, assessoramento escolar, apoio técnico operacional, coordenação regional de educação e coordenação de programas educacionais (MATO GROSSO DO SUL, 2001). O magistério municipal caracteriza-se pelo conjunto de profissionais da educação que exercem atividades de docência e as funções técnico-pedagógicas que compreendem a administração, a supervisão, a inspeção e a orientação educacional nas unidades de ensino e no órgão central, representado pela Secretaria Municipal de Educação (CAMPO GRANDE, 1998a).

Isso posto, a legislação nacional que instituiu o Fundef dispôs, em seu artigo $9^{\circ}$, que os recursos desse fundo para remuneração seriam para os professores "do ensino fundamental público, em efetivo exercício no magistério" (BRASIL, 1996a). Da mesma forma, o Fundeb definiu, em seu artigo 22, que o montante de seus recursos pertinentes à remuneração seria para "os profissionais do magistério da educação básica em efetivo exercício na rede pública” (BRASIL, 2007a). Ainda o Fundeb, no parágrafo único do artigo 22, inciso primeiro, dispõe que profissionais do magistério são os "docentes, profissionais que oferecem suporte pedagógico direto ao exercício da docência: direção ou administração escolar, planejamento, inspeção, supervisão, orientação 
educacional e coordenação pedagógica", e, no inciso segundo do mesmo parágrafo, normatiza que efetivo exercício seria a

[...] atuação efetiva no desempenho das atividades de magistério previstas no inciso II deste parágrafo associada à sua regular vinculação contratual, temporária ou estatutária, com o ente governamental que o remunera, não sendo descaracterizado por eventuais afastamentos temporários previstos em lei, com ônus para o empregador, que não impliquem rompimento da relação jurídica existente (BRASIL, 2007a).

\section{Os fundos contábeis e a valorização do magistério}

O Fundef foi instituído pela Emenda Constitucional $\mathrm{n}^{\circ}$ 14/1996, regulamentado pela Lei no $9.424 / 1996$ e pelo Decreto Federal $\mathrm{n}^{\circ} 2.264 / 1997$ (BRASIL, 1996b, 1996a, 1997) e vigorou até 2006. O Fundo foi mantido com $15 \%$ dos recursos provenientes de alguns impostos e transferências vinculadas constitucionalmente, o que corresponde a $60 \%$ dos $25 \%$ determinados pelo artigo 212 da Constituição Federal de 1988 (BRASIL, 1988). Os recursos do Fundef foram distribuídos, em cada unidade federada, entre o governo estadual e os governos municipais, com base no número de alunos matriculados nas respectivas redes de ensino, na etapa do ensino fundamental.

Por isso mesmo, os recursos deveriam ser gastos, exclusivamente, com o ensino fundamental, com o emprego do percentual de pelo menos $60 \%$ para a remuneração dos profissionais em efetivo exercício nessa etapa da educação básica. Os 40\% restantes poderiam ser gastos com quaisquer despesas do ensino fundamental, desde que realizadas como Manutenção e Desenvolvimento do Ensino (MDE), conforme o disposto na Lei de Diretrizes e Bases da Educação Nacional (BRASIL, 1996c).

O Fundef descentralizou os recursos do financiamento para MDE, ao alterar o artigo 60 do Ato das Disposições Constitucionais Transitórias e o artigo 211 da Constituição Federal de 1988 (BRASIL, 1988), quando retirou da União a responsabilidade de aplicar montantes de recursos significativos na educação básica (PINTO, 2002). Assim, à União coube a função redistributiva e supletiva em relação às condições de manutenção e desenvolvimento do ensino dos estados, 
Distrito Federal e municípios. Essa alteração da função da União, propalada pela mídia com grande empenho, camuflou a regressão da União no investimento da educação básica, em que pese o discurso de que investir nessa etapa da educação teria sido a prioridade do governo federal (OLIVEIRA, 2000).

Não obstante, de acordo com a análise do governo federal no documento Balanço do Primeiro Ano do Fundef 1999, o Fundo cumpriu, já no primeiro ano de sua execução, os objetivos estratégicos de justiça social, equidade, descentralização, melhoria da qualidade e valorização do magistério (BRASIL, 1999). De acordo com o documento, o Fundo apresentou impactos extremamente significativos que indicariam o acerto e o alcance das reformas implementadas, com efeitos imediatos na elevação do nível salarial do magistério do ensino fundamental, de gastos com atividades de capacitação docente, transporte escolar, reforma e ampliação de escolas e aquisição de equipamento e material didático (BRASIL, 1999).

Sobre a elevação salarial do magistério, principalmente Arelaro (1999) analisa que as estimativas apresentadas pelo documento Balanço do Primeiro Ano do Fundef 1999 explicitaram o que já estava previsto: o aumento salarial se deu nas redes de ensino das regiões nordeste e norte do país, onde os salários já eram baixíssimos, inclusive com salários com valores menores que o salário mínimo nacional. Ainda a autora considera que a medida provocou discrepâncias entre os salários dos professores do ensino fundamental e os salários dos professores que atuavam em outras etapas da educação básica (ARELARO, 1999).

O Fundef foi substituído, em 2007, pelo Fundo de Manutenção e Desenvolvimento da Educação Básica e de Valorização dos Profissionais da Educação (Fundeb), que abrangeu, ao contrário do Fundef, toda a educação básica. Cabe lembrar que:

Dos recursos do fundo, no mínimo, 60\% serão destinados ao pagamento da remuneração dos profissionais do magistério da educação básica. Esta destinação, na atual proposta, sofreu uma redução significativa, em relação à proposta original do Fundeb, em que se previa a destinação de $80 \%$ dos recursos totais do fundo para a remuneração dos profissionais da educação. Também, na proposta original, previa-se um fundo permanente (DEPARTAMENTO Intersindical de Estatística e Estudos Socioeconômicos, 2005, p.6). 
De fato, o fundo permanente foi substituído, no Fundeb, por um prazo de até 2020 para a utilização de seus recursos para pagamentos de salários.

A base do Fundeb é semelhante à do Fundef: ambos são fundos de natureza contábil. O âmbito de atuação de cada fundo é entre os estados e seus municípios, com a redistribuição dos recursos vinculados de acordo com o número de matrículas de cada rede de ensino. A União continuou a determinar o valor mínimo nacional por aluno; porém, ele é diferenciado para cada etapa e modalidade de ensino e complementa financeiramente os estados que não conseguem atingir o valor mínimo por aluno definido nacionalmente.

A vinculação de recursos constitucionais para MDE continuou nos mesmos percentuais indicados pela Constituição Federal de 1988, de, no mínimo, 18\%, para a União, e 25\%, para estados e municípios, provenientes das receitas de impostos e transferências (BRASIL, 1988). Na composição dos impostos vinculados para a formação do Fundeb, ficaram de fora os de origem municipal. E o salário-educação, antes restrito ao ensino fundamental, passou a financiar toda a educação básica.

No estado de Mato Grosso do Sul, o Fundef foi implantado mediante a aprovação da Lei $n^{\circ} 1.819 / 1998$, e o Fundeb, pela Lei $n^{\circ}$ 3.368/2007, cujas legislações regulamentaram também os respectivos Conselhos Estaduais de Acompanhamento e Controle Social dos recursos dos fundos (MATO GROSSO DO SUL, 1998a, 2007).

No município de Campo Grande, o Fundef e o Fundeb foram instalados automaticamente em 1998 e 2007. Apenas os Conselhos de Acompanhamento e Controle Social, tanto do Fundef quanto do Fundeb, é que foram estabelecidos por meio de legislação específica municipal - respectivamente pelas Leis $\mathrm{n}^{\circ} 3.405 / 1997$ e $\mathrm{n}^{\circ} 4.448 / 2007$ (CAMPO GRANDE, 1997; 2007a).

Há que se destacar, aqui, um movimento importante construído pelo estado de Mato Grosso do Sul, que foi seguido por vários de seus municípios, provocou impacto significativo no âmbito das finanças públicas e foi emblemático para o campo do financiamento do ensino, particularmente no que tange à valorização do magistério.

Trata-se da aprovação da Emenda Constitucional no 06/1997 (MATO GROSSO DO SUL, 1997), que substituiu a redação do artigo 
198 da Constituição Estadual, com vistas a reduzir de $30 \%$ para $25 \%$ os recursos para MDE no estado.

De fato, frente à implantação do Fundef, a "[...] unidade federada se precaveu por meio de medidas legais, diminuindo dispêndios para MDE, o que inclusive se refletiu na valorização do magistério, pois menos recursos para MDE, menos recursos para salários" (FERNANDES; OLIVEIRA, 2011, p.7).

O mesmo movimento de redução no percentual de recursos para MDE foi observado no município de Campo Grande. A Lei Orgânica do Município (CAMPO GRANDE, 1990), até 1997, previa percentual de 30\%, e a Emenda no 08/1998 reduziu o percentual para 25\% (CAMPO GRANDE, 1998b). A redução para 25\% do percentual de impostos e transferências vinculados diminuiu o valor do custo/ aluno/ano do ensino fundamental de RS $1.173,53^{2}$ em 1997 , para $R \$$ 932,64 em 1998.

Tais fatos, na ocasião, foram denunciados pela Federação dos Trabalhadores em Educação de Mato Grosso do Sul (FETEMS) e levaram a categoria dos professores a protagonizar mais uma greve. Não obstante, a categoria não conseguiu o acúmulo suficiente no processo de correlação de forças sociais para impedir a ação dos Poderes Executivos com o apoio dos Poderes Legislativos estadual e municipal (FERNANDES, 2003).

\section{A remuneração salarial dos professores da rede estadual e da rede municipal de ensino no município de Campo Grande}

O pacto pela valorização do magistério, firmado em outubro de 1994, no Governo Itamar Franco, resultante do processo do Plano Decenal de Educação, apesar de ter sido rompido em 1995, no Governo Fernando Henrique Cardoso (FERNANDES; RODRIGUEZ, 2011), lastreou um conjunto de proposições que aprofundou o vínculo entre a profissionalização do magistério e a qualidade da educação. Assim, em 1998, com a implantação do Fundef, foram retomadas as expectativas em relação à valorização, por meio de melhores condições de trabalho e de carreira e, também, por meio de salários. 
Nesse contexto, de acordo com a legislação nacional, os Planos de Cargos, Carreiras e Remunerações (PCCRs), em cada unidade subnacional, deveriam constituir-se em um conjunto de normas com vistas a regulamentar as condições de acesso e o processo de movimentação na profissão, determinando a evolução funcional por nível, categoria e classe. Deveriam tratar, ainda, dos adicionais, das gratificações e incentivos e dos critérios e escalas da remuneração por meio da progressão funcional vertical (graduação e pós-graduação) e horizontal (tempo de serviço).

A partir da implantação dos PCCRs, os professores leigos, de acordo com a legislação, deveriam qualificar-se ou passariam a integrar um quadro em extinção, pois, para integrar o quadro permanente, deveriam ter habilitação necessária para o nível em que estivessem atuando. O ingresso na carreira do magistério se daria, exclusivamente, por concurso público de provas e títulos; o piso salarial profissional seria definido pelos sistemas de ensino.

A jornada de trabalho não poderia ser maior que 40 horas semanais, permitindo-se, contudo, jornadas menores. Foi prevista uma proporção de horas-atividades entre $20 \%$ e $25 \%$ do total da jornada, constituídas de trabalho individual e coletivo.

Não obstante os dispositivos legais nacionais estabelecidos, Gatti e Barreto informam que:

Essa profissão até o final dos anos 1990 não contava na maioria dos municípios com um marco regulatório. Isto vem a se realizar em maior escala, na segunda metade dos anos 1990, na medida da implementação pelo governo federal do Fundo de Desenvolvimento do Ensino Fundamental, hoje da Educação Básica (Fundef/Fundeb), e das exigências postas como condição para o recebimento de retribuições financeiras para os sistemas estaduais e municipais de educação escolar. Portanto, na maioria das instâncias de gestão da educação pública, não havia preocupação política com o estatuto de carreira dos docentes, seja da educação infantil, seja do ensino fundamental, seja do ensino médio (GATTI; BARRETO, 2009, p.248249).

De fato, o marco regulatório para o magistério estadual, no estado de Mato Grosso do Sul, antecedeu ao do município de Campo Grande. Assim, a Lei Complementar no 87/2000 (MATO GROSSO DO SUL, 2000a) reformulou o Estatuto do Magistério e é o que está 
em vigor, enquanto que, no município de Campo Grande, a Lei Complementar $n^{\circ}$ 19/1998 (CAMPO GRANDE, 1998a) estabeleceu o Plano de Carreira e Remuneração do Magistério Público da Prefeitura Municipal de Campo Grande (PCRM), como já mencionado neste trabalho.

Tais marcos regulatórios, no período aqui considerado, disciplinaram a força de trabalho docente em termos quantitativos, como mostra a Tabela 1:

TABELA 1 - Total de funções docentes até $2006^{*}$ e cadastro único de professor a partir de 2007 atuando na rede estadual e na rede municipal de ensino no município de Campo Grande (1998-2000-2006-2007 e 2010)

\begin{tabular}{c|c|c} 
Ano & Rede Estadual & Rede Municipal de Campo Grande \\
\hline $\mathbf{1 9 9 8}$ & 3.615 & 2.637 \\
$\mathbf{2 0 0 0}$ & 4.046 & 2.971 \\
$\mathbf{2 0 0 6}$ & 3.885 & 4.340 \\
$\mathbf{2 0 0 7}$ & 3.324 & 3.957 \\
$\mathbf{2 0 1 0}$ & 3.307 & 4.268
\end{tabular}

Fonte: BRASIL. Instituto Nacional de Estudos e Pesquisas Educacionais Anísio Teixeira (INEP). Microdados do Censo Escolar, 1998, 2000, 2006, 2007b e 2010.

* A partir de 2007, o Censo Escolar passou a fazer cadastro único do professor.

O quantitativo de professores que atuou na rede estadual de ensino diminuiu em 8,5\%, enquanto que, na rede municipal, houve aumento de 61,8\% no período de 1998 a 2010. Obviamente que o aumento de professores na rede municipal de ensino no período está diretamente vinculado à municipalização do ensino fundamental promovido pelo Fundef. Cabe lembrar que a rede estadual de ensino perdeu $54 \%$ das matrículas do ensino fundamental no período. De fato, em 1998, o número de alunos da rede estadual de ensino fundamental, no município de Campo Grande, era de 64.328; em 2010, registraram-se 29.590 matrículas (BRASIL, 1998, 2010).

Dois pontos são importantes de se destacar, tanto no estatuto do magistério estadual, quanto no PCCR do município de Campo Grande: a valorização salarial por meio do tempo de serviço e pela titulação. Na promoção por tempo de serviço, o professor passa de uma classe para a outra subseqüente, contando-se o número de anos necessários previstos nas respectivas leis. 
A titulação leva em conta o grau de escolaridade do professor. $\mathrm{Na}$ rede estadual de ensino, são quatro graduações: professor com ensino médio magistério, professores com licenciatura plena (graduação), professores com pós-graduação (360 horas) e professor com curso de mestrado. $\mathrm{Na}$ rede municipal de ensino, além das quatro graduações reconhecidas pela rede estadual, também está previsto o professor com curso de doutorado, perfazendo um total de cinco graduações.

A Tabela 2 abaixo demonstra o salário base dos professores nos três níveis de graduação em que está alocado o maior quantitativo de professores das duas redes de ensino: habilitação ensino médio, licenciatura plena e professores com pós-graduação - especialização. A Tabela também apresenta o salário base do professor da rede estadual de ensino a partir de 2000, pois, com a promulgação da Lei Complementar $n^{\circ}$ 87/2000 (MATO GROSSO DO SUL, 2000a), houve uma reorganização da carreira e da promoção funcional.

Pontua-se que, no período que antecedeu a implantação do Fundef, o magistério estadual teve, no ano de 1995, um reajuste salarial por meio indireto, pela Lei n ${ }^{\circ}$ 1.562/1995 (MATO GROSSO DO SUL, 1995), que regulamentou a chamada "antecipação salarial" de $20 \%$, que não era incorporada ao salário, mas era paga mensalmente, e que permaneceu até o ano de 1999. Nos anos de 1996 e 1997, os salários não tiveram alteração. Em 1998, a Lei no 1.837 (MATO GROSSO DO SUL, 1998b) concedeu somente um abono salarial de R $\$ 70,00$ (setenta reais), que também permaneceu até 1999.

TABELA 2 - Demonstrativo do salário base dos professores da rede estadual de ensino - 20 horas (2000-2006-2007-2010)

\begin{tabular}{c|c|c|c|c|c} 
Habilitação & Vencimento & $\mathbf{2 0 0 0}$ & $\mathbf{2 0 0 6}$ & $\mathbf{2 0 0 8}$ & $\mathbf{2 0 1 0}$ \\
\hline Ensino Médio & Inicial & 418,19 & 376,79 & 359,56 & 625,43 \\
\cline { 2 - 6 } Magistério & Final & 585,46 & 606,62 & 578,89 & $1.006,94$ \\
\hline $\begin{array}{c}\text { Licenciatura Plena } \\
\text { (Graduação) }\end{array}$ & Inicial & 627,28 & 565,19 & 539,35 & 938,15 \\
\cline { 2 - 6 } & Final & 878,19 & 909,94 & 868,34 & $1.510,41$ \\
\hline $\begin{array}{c}\text { Pós-Graduação } \\
\text { (Especialização) }\end{array}$ & Inicial & 669,10 & 602,87 & 575,30 & $1.000,69$ \\
\cline { 2 - 6 } & Final & 936,75 & 970,60 & 926,22 & $1.611,11$
\end{tabular}

Fonte: MATO GROSSO DO SUL. Diário Oficial do Estado de Mato Grosso do Sul (DIOSUL), 2000b, 2006, 2008 e 2009. Valores Indexados pelo INPC (dez./2010).

* Os dados salariais do ano de 2010 foram publicados no DIOSUL de $\mathrm{n}^{0} 7.601$, de 10 de dezembro de 2009. 
Registra-se que a progressão por tempo de serviço, em cada habilitação, inicia-se na classe $\mathrm{A},{ }^{4}$ de zero a três anos, e a partir da classe B, de cinco em cinco anos. A partir de 2003, a progressão funcional foi ampliada até a classe $\mathrm{H}$. Com essa alteração, o docente leva 33 anos para galgar toda a progressão por tempo de serviço.

Destaca-se que o movimento do salário base, durante a implementação do Fundef (2000 a 2006), imprimiu um salário inicial que, nas três habilitações, diminuiu em 9,89\%. Ou seja, esses índices negativos, durante o Fundef, em todas as habilitações, indicam que os reajustes foram menores que a inflação do período e que não houve estímulo, em termos de salários, aos novos professores que iniciaram na carreira, como mostra a Tabela 2. Em relação ao salário final, nas três habilitações, o aumento foi de 3,61\% no período. Pelos valores apresentados, o Fundef, além de não promover impactos positivos no salário do professor da rede estadual de ensino, ainda, durante sua vigência, os salários foram reduzidos. No que tange ao movimento do salário base nos quatro primeiros anos de Fundeb (2007 a 2010), na rede estadual de ensino, observou-se que o reajuste do salário inicial e do salário final foi de $73,94 \%$, portanto, o período do Fundeb trouxe uma recuperação salarial que não houve à época do Fundef, situação que pode ser proporcional ao aumento de impostos de base estadual na composição desse fundo.

Quando comparado na série de 2000 a 2010, o reajuste do salário inicial do professor nas três habilitações foi de 49,5\%. O salário final teve reajuste de $72 \%$ nas três habilitações. A partir dos dados registrados, pode-se inferir que foi a partir do Fundeb, que, efetivamente, os salários dos professores da rede estadual de ensino apresentaram a recuperação salarial proposta pelos fundos.

Tal recuperação salarial, contudo, deve ser observada no contexto tanto de redução de matrículas quanto da contratação de professores na rede estadual de ensino - como mostra a Tabela 1 - em razão do processo de municipalização e descentralização da política educacional durante a vigência do Fundef. Assim, quando o Fundeb começou a vigorar, a rede apresentou estabilidade no que tange à relação entre matrículas e contratação docente. Obviamente, tal quadro se mostrou favorável às reposições salariais, todavia, sem reparação de perdas históricas. 
Na Tabela 3, verifica-se o vencimento base dos professores da rede municipal de ensino do município de Campo Grande para os anos de 1998 e 2006 (início e final do Fundef) e 2007 (início do Fundeb) e 2010.

TABELA 3 - Demonstrativo do salário base dos professores da rede municipal de Campo Grande - 20 horas (1998-2006-2007-2010)

\begin{tabular}{c|c|c|c|c|c} 
Habilitação & Vencimento & $\mathbf{1 9 9 8}$ & $\mathbf{2 0 0 6}$ & $\mathbf{2 0 0 7}$ & $\mathbf{2 0 1 0}$ \\
\hline Ensino Médio & Inicial & 452,29 & 514,42 & 552,26 & 621,42 \\
\cline { 2 - 6 } Magistério & Final & 757,55 & 947,80 & $1.017,52$ & $1.144,91$ \\
\hline Licenciatura Plena & Inicial & 587,97 & 745,92 & 828,40 & 932,13 \\
\cline { 2 - 6 } (Graduação) & Final & 984,81 & $1.374,30$ & $1.526,28$ & $1.717,37$ \\
\hline $\begin{array}{c}\text { Pós-Graduação } \\
\text { (Especialização) }\end{array}$ & Inicial & 646,78 & 820,51 & 911,24 & $1.025,34$ \\
\cline { 2 - 6 } & Final & $1.082,76$ & $1.511,73$ & $1.678,90$ & $1.889,11$
\end{tabular}

Fonte: CAMPO GRANDE. Diário Oficial do Município de Campo Grande (DIOGRANDE), 1998c, 2006a, 2007b e 2010. Valores Indexados pelo INPC (dez./2010).

O movimento do salário base da rede municipal do município de Campo Grande, durante o Fundef (1998 a 2006), para o salário inicial, significou que, para o docente habilitado com o ensino médiomagistério, houve um reajuste de $13,73 \%$, menor que para os demais docentes, que tiveram reajuste de $26,86 \%$. Para o salário final, o reajuste para o docente com formação no ensino médio-magistério foi de 25,11\%; nas demais habilitações, o reajuste foi de 39\%.

Durante os quatro primeiros anos do Fundeb (2007 a 2010), o movimento do salário base dos docentes da rede municipal de ensino exibiu a seguinte dinâmica: em todas as habilitações, o reajuste do vencimento base, tanto o inicial quanto o final, foi de 12,5\%.

De fato, quando se compara a série de 1998 a 2010, os menores reajustes foram do salário inicial e final na habilitação ensino médiomagistério, respectivamente, de $37,3 \%$ e $51,13 \%$ de reajuste nesses 12 anos de implementação dos fundos contábeis. Nas outras habilitações, o reajuste foi de $58 \%$ no salário inicial e 74,38\% no salário final.

Pontua-se que, no caso da rede municipal de ensino de Campo Grande, as reposições salariais no período mostraram um perfil mais diversificado que o da rede estadual de ensino. Tal situação tem sido coerente com o curso da política educacional de municipalização e descentralização do ensino no município, tanto quanto na rede estadual de ensino, como já mencionado. 
O que permaneceu em comum, em ambas as redes, no período, foi que a política salarial não recuperou perdas históricas do magistério: antes, ateve-se a garantir minimamente a reprodução da força de trabalho.

\section{Considerações finais}

De acordo com Braz (2008), a valorização dos professores com cursos de graduação e de pós-graduação deveria ser motivada por melhores salários, o que garantiria a atratividade na carreira.

De fato, a atratividade na carreira ou a reprodução da força de trabalho podem ser proporcionais a imperativos que se objetivam com vistas às garantias de condições materiais de existência. Tal condição, no entanto, prescinde de outras que devem ser construídas na historicidade de formas objetivas e subjetivas. Particularmente, no caso da força de trabalho docente, sobressai-se a concepção de Estado vigente, decorrente dela a política educacional e, sobretudo, o grau de organização dessa força de trabalho.

No caso do magistério, no município de Campo Grande, tanto na rede estadual quanto na rede municipal de ensino, historicamente, esteve em pauta, como forma de garantir condições materiais de existência, por um lado, a isonomia de salários, e, por outro, um piso salarial vinculado em proporções quantitativas ao salário mínimo nacional (FEDERAÇÃO dos Trabalhadores em Educação de Mato Grosso do Sul, 2011).

Com efeito, a instituição do PSPN (BRASIL, 2008) é uma medida de indução do Governo Federal que parece atentar para as duas questões acima mencionadas. De fato, a instituição do PSPN poderia minimizar impactos substantivos nas distorções geradas pelas desigualdades regionais e locais no que tange à matéria salarial docente.

Diante disso, a valorização do magistério, por meio de salários, que não foi possível de se materializar plenamente, no contexto das políticas de fundos, encontrou, no poder de indução da União, uma nova oportunidade, via instituição do PSPN.

Essa oportunidade de valorização docente, por meio do PSPN, que foi contemporânea ao Fundeb, contudo, provocou estreme- 
cimentos consideráveis no âmbito das relações federativas brasileiras (FERNANDES; RODRIGUEZ, 2011).

A propósito, entre os impetrantes da Ação Direta de Inconstitucionalidade (ADIn) de $\mathrm{n}^{\circ} 4.167 / 2008$ sobre a Lei $\mathrm{n}^{\circ}$ 11.738/2008 (BRASIL, 2008b, 2008a), encontra-se o atual governador do estado de Mato Grosso do Sul. ${ }^{5}$ Alegaram os governadores, em 2008, que a Lei 11.738/2008 (BRASIL, 2008a) quebraria regras de autonomia federativa.

Em que pese o ganho de causa em favor da União na questão do PSPN, ainda em 2008, em 2010, último ano de análise considerado neste trabalho, a implantação do PSPN permanecia em aberto nas unidades subnacionais, tanto porque instituiu um piso, como também porque remeteu a novas composições de jornada de trabalho docente.

Assim, como até 2010 o estado de Mato Grosso do Sul e o município de Campo Grande não haviam implantado o PSPN, a política salarial docente se efetivou na articulação entre a disponibilidade de recursos financeiros provenientes (dos 60\% no mínimo ao ano) dos fundos para salários com a implementação da descentralização e da municipalização do ensino.

Nessa conjuntura, a rede estadual de ensino do estado de Mato Grosso do Sul, a partir do Fundeb, passou a operar com indicadores de maior estabilidade, em razão da descentralização e da municipalização do ensino. Tal fato repercutiu nos salários docentes da rede em termos de reajustes, contudo, sem recuperar ao menos as perdas salariais impostas durante o Fundef.

$\mathrm{Na}$ rede municipal de ensino de Campo Grande, os reajustes salariais permaneceram em um padrão concernente ao amplo processo de municipalização do ensino fundamental, a alta demanda e o baixo atendimento à educação infantil. Nesse contexto, os recursos dos fundos não foram suficientes para um impacto salarial importante. Aguarda-se o que virá com a implantação do PSPN, não pelo piso salarial em si: mas, sobretudo, pela recomposição das jornadas de trabalho docente, tema que gerará aumentos significativos nas folhas de pagamento do pessoal do magistério. 


\section{NOTAS}

1 Este trabalho integra a pesquisa nacional Remuneração de professores de escolas públicas de educação básica: configurações, impactos, impasses e perspectivas, financiada pela CAPES/INEP/SECAD - Observatório da Educação (Edital nº 001/2008) e realizada junto ao Centro de Estudos e Pesquisas em Políticas Públicas de Educação (CEPPPE) da Faculdade de Educação da Universidade de São Paulo. A pesquisa é coordenada nacionalmente pelo Prof. Dr. Rubens Barbosa de Camargo e desenvolvida em doze estados (São Paulo, Paraná, Rio Grande do Sul, Santa Catarina, Mato Grosso do Sul, Mato Grosso, Paraíba, Piauí, Roraima, Pará, Minas Gerais e Rio Grande do Norte). Envolve nove programas de pós-graduação em educação (USP, UFPA, UFPI, UFPB, UFRN, UEMG, UFMS, UFPR, UNISUL), contando, ainda, com quatro grupos colaboradores de pesquisa (USP-RP, UNIFESP, UFMT, UFRGS).

2 Valores indexados pelo INPC/dezembro de 2010. Pontua-se que o grupo nacional da pesquisa, por uma questão de padronização de dados, deliberou por indexar os valores financeiros e contábeis sempre pelo INPC/dezembro de 2010.

3 Idem.

4 Neste texto, trabalhou-se com o vencimento inicial, classe A, e o vencimento final, classe $\mathrm{H}$.

5 Trata-se de André Puccinelli. Foi prefeito de Campo Grande no período de 1997 a 2005. Foi eleito governador do Estado de Mato Grosso do Sul em 2006 e reeleito em 2010.

\section{REFERÊNCIAS}

ARELARO, L. R. G. Financiamento e qualidade da educação brasileira. Algumas reflexões sobre o documento "Balanço do primeiro ano do Fundef - Relatório MEC". In: DOURADO, L. F. (Org.). Financiamento da educação básica. Goiânia: Editora UFG; Campinas: Autores Associados, 1999. p.27-45.

BRASIL. Constituição (1988). Constituição da República Federativa do Brasil. Brasília: Senado Federal, 1988.

BRASIL. Lei n 9.424, de 24 de dezembro de 1996. Dispõe sobre o Fundo de Manutenção e Desenvolvimento do Ensino Fundamental e de Valorização do Magistério, na forma prevista no art. 60 do ADCT, e dá outras providências. Brasília, 1996a. Disponível em: <http://www.planalto.gov.br>. Acesso em: 05 abr. 2009.

BRASIL. Constituição (1988). Emenda Constitucional no 14, de 12 de setembro de 1996. Modifica o artigo 34 e o Título VIII, Capítulo III da C.F. e o artigo 60 do ADCT. Brasília, 1996b. Disponível em: <http://www.planalto.gov.br>. Acesso em: 10 ago. 2010.

BRASIL. Lei no 9.394, de 20 de dezembro de 1996. Estabelece as diretrizes e bases da educação nacional. Brasília, 1996c. Disponível em: <http://www.planalto.gov.br>. Acesso em: 05 abr. 2009. 
BRASIL. Decreto $n^{\circ} 2.264$, de 27 de junho de 1997. Regulamenta a Lei no 9.424, de 24 de dezembro de 1996, no âmbito federal, do Fundo de Manutenção e Desenvolvimento do Ensino Fundamental e determina outras providências. Brasília, 1997. Disponível em: <http://www.planalto.gov.br>. Acesso em: 05 fev. 2013.

BRASIL. Ministério da Educação e Cultura. Instituto de Estudos e Pesquisas Educacionais Anísio Teixeira (INEP). Microdados do censo escolar. Brasília, 1998.

BRASIL. Ministério da Educação e Cultura. Balanço do primeiro ano do Fundef. Brasília, 1999. Disponível em: <http//www.mec.gov>. Acesso em: 20 out. 2000.

BRASIL. Ministério da Educação e Cultura. Instituto de Estudos e Pesquisas Educacionais Anísio Teixeira (INEP). Microdados do censo escolar. Brasília, 2000.

BRASIL. Ministério da Educação. Instituto de Estudos e Pesquisas Educacionais Anísio Teixeira (INEP). Microdados do censo escolar. Brasília, 2006.

BRASIL. Lei no 11.494, de 20 de junho de 2007. Regulamenta o Fundo de Manutenção e Desenvolvimento da Educação Básica e de Valorização dos Profissionais da Educação - Fundeb e dá outras providências. Brasília, 2007a. Disponível em: <http://www.planalto. gov.br.>. Acesso em: 05 maio 2011.

BRASIL. Ministério da Educação. Instituto de Estudos e Pesquisas Educacionais Anísio Teixeira (INEP). Microdados do censo escolar. Brasília, 2007b.

BRASIL. Lei no 11.738, de 16 de julho de 2008. Regulamenta a alínea "e" do inciso III do caput do art. 60 do Ato das Disposições Constitucionais Transitórias, para instituir o piso salarial profissional nacional para os profissionais do magistério público da educação básica. Brasília, 2008a. Disponível em: <http://www.planalto.gov.br>. Acesso em: 10 ago. 2010.

BRASIL. Supremo Tribunal Federal. Petição Inicial. Ação Direta de Inconstitucionalidade, 28/10/2008, 2008b. Disponível em:

$<$ www.stf.jus.br/portal/processo/verProcessoAndamento.asp?numero $=4167 \&$ clas$\mathrm{se}=\mathrm{ADI} \&$ origem $=\mathrm{AP} \&$ recurso $=0 \&$ tipoJulgamento $=\mathrm{M}>$. Acesso em: 03 mar. 2010.

BRASIL. Ministério da Educação. Instituto de Estudos e Pesquisas Educacionais Anísio Teixeira (INEP). Microdados do censo escolar. Brasília, 2010.

BRAZ, T. P. O financiamento do ensino médio da rede estadual de Mato Grosso do Sul (1996 a 2006). 263 f. 2008. Tese (Doutorado em Educação) - Faculdade de Educação, Universidade Estadual de São Paulo, São Paulo, 2008.

CAMPO GRANDE. Câmara Municipal de Campo Grande. Lei Orgânica do Município de Campo Grande - MS, de 04 de abril de 1990. Campo Grande, 1990.

CAMPO GRANDE. Lei ñ 3.405, 01 de dezembro de 1997. Cria o Conselho Municipal de Acompanhamento e Controle Social do Fundo de Manutenção e Desenvolvimento do Ensino Fundamental e de Valorização do Magistério. Campo Grande, 1997. Disponível em: <http://www.camara.ms.gov.br>. Acesso em: 10 out. 2010.

CAMPO GRANDE. Lei Complementar $n^{\circ}$ 19, de 15 de julbo de 1998. Dispõe sobre o Plano de Carreira e Remuneração do Magistério Público da Prefeitura Municipal de Campo Grande e dá outras providências. Campo Grande, 1998a.

CAMPO GRANDE. Câmara Municipal. Emenda nº 8, de 29 de junho de 1998, altera a Lei Orgânica do Município de Campo Grande. Campo Grande, 1998b. Disponível em: $<$ http:/ / www.camara.ms.gov.br/index.php?conteudo=arquivo_word\&tb=lei_organica>. Acesso em: 16 jun. 2011. 
CAMPO GRANDE. Lei no 3.442, de 24 de março de 1998. Dispõe sobre Reajuste Salarial. Diário Oficial da Prefeitura Municipal de Campo Grande (DIOGRANDE). Campo Grande, Imprensa Oficial, n.128, 16 jun. 1998c. Seção 2, p.15-16.

CAMPO GRANDE. Decreto n ${ }^{\circ} 9.678$, de 13 de julho de 2006. Dispõe sobre o complemento do reajuste aplicado nas tabelas de vencimentos dos Servidores Municipais e dá outras providências. Diário Oficial da Prefeitura Municipal de Campo Grande (DIOGRANDE). Campo Grande, Imprensa Oficial, n.2.098, 14 jul. 2006. Seção 1, p.2. CAMPO GRANDE. Lei ñ 4.448 de 27 de fevereiro de 2007. Dispõe sobre a criação do Conselho Municipal de Acompanhamento e Controle Social do Fundo de Manutenção e Desenvolvimento da Educação Básica e de Valorização dos Profissionais da Educação - FUNDEB de Campo Grande - MS. Campo Grande, 2007a.

CAMPO GRANDE. Decreto no 9.809, de 02 de janeiro de 2007. Divulga a tabela de vencimento dos servidores detentores do cargo de professor e dá outras providências. Diário Oficial da Prefeitura Municipal de Campo Grande (DIOGRANDE). Campo Grande, Imprensa Oficial, n.2.211, 03 jan. 2007b. Seção 1, p.1-3.

CAMPO GRANDE. Lei no 4835, de 30 de abril de 2010. Dispõe sobre a revisão geral de remuneração dos servidores do poder executivo, e dá outras providências. Diário Oficial da Prefeitura Municipal de Campo Grande (DIOGRANDE). Campo Grande, Imprensa Oficial, n.3.024, 27 jan. 2010. Seção 1, p.2-3.

DEPARTAMENTO Intersindical de Estatística e Estudos Socioeconômicos (DIEESE). Nota Técnica - o Fundeb e o financiamento público da educação, n ${ }^{\circ} 7$, out. 2005. Disponível em: <http://www.dieese.org.br/notatecnica/notatecFundeb.pdf>. Acesso em: 05 fev. 2013.

FEDERAÇÃO dos Trabalhadores em Educação de Mato Grosso do Sul. PSPN: hora de decisão e de contra-ataque às investidas reacionárias. Campo Grande, 2011. Disponível em: <http://www.fetems.org.br/novo/nw.php?nw=3203>. Acesso em: 12 fev. 2013.

FERNANDES, M. D. E. Políticas públicas de educação: o financiamento da rede estadual de ensino de Mato Grosso do Sul (1991 a 1994). 250 f. 2001. Tese (Doutorado em Educação) - Faculdade de Educação, Universidade Estadual de Campinas, Campinas, 2001.

FERNANDES, M. D. E. O estado de Mato Grosso do Sul e os recursos vinculados constitucionalmente para a educação. In: SENNA, E. (Org.). Trabalho, educação e política pública. Campo Grande: UFMS, 2003. p.221-241.

FERNANDES, M. D. E.; OLIVEIRA, R. T. C. de. O Fundef no Estado de Mato Grosso do Sul: balanço da política de financiamento para o ensino fundamental (1998 a 2006). FINEDUCA - Revista de Financiamento da Educação, Porto Alegre, v.1, n.4, p.120, 2011.

FERNANDES, M. D. E.; RODRIGUEZ, M. V. O processo de elaboração da Lei nº. 11.738/2008 (Lei do Piso Salarial Profissional Nacional para Carreira e Remuneração docente): trajetória, disputas e tensões. Revista HISTEDBR, Campinas, n.41, p.88-101, mar. 2011.

GATTI, B. A.; BARRETO, E. S. de S. Professores do Brasil: impasses e desafios. Brasília: UNESCO, 2009. 
MATO GROSSO DO SUL. Assembleia Legislativa. Lei Complementar n 35, de 12 de janeiro de 1988. Dispõe sobre o Estatuto do Magistério Estadual de Mato Grosso do Sul e dá outras providências. Campo Grande, 1988.

MATO GROSSO DO SUL. Constituição do Estado de Mato Grosso do Sul. Departamento de Imprensa Oficial de Mato Grosso do Sul. Campo Grande, 1989. Disponível em: $<$ http//www.ms.gov.br>. Acesso em: 05 ago. 2010.

MATO GROSSO DO SUL. Lei n 1562, de 24 de março de 1995. Concede antecipação salarial aos servidores civis e militares da administração direta, das autarquias e das fundações do Poder Executivo, e dá outras providências. Campo Grande, 1995. Disponível em: <http//www.ms.gov.br>. Acesso em: 15 fev. 2010.

MATO GROSSO DO SUL. Assembleia Legislativa. Emenda Constitucional n. 06, de 07 de julho de 1997. Campo Grande, 1997.

MATO GROSSO DO SUL. Lei n ${ }^{\circ} 1.819$, de 08 de janeiro de 1998. Institui o Fundo Estadual de Manutenção e Desenvolvimento do Ensino Fundamental e de Valorização do Magistério e dispõe sobre o Conselho de Acompanhamento e Controle Social do Fundo e dá outras providências. Campo Grande, 1998a. Disponível em: <http//www.ms.gov.br>. Acesso em: 05 ago. 2010.

MATO GROSSO DO SUL. Lei $n^{0} 1.837$, de 06 de abril de 1998. Concede abono salarial aos servidores que menciona e dá outras providências. Campo Grande, 1998b. Disponível em: <http//www.ms.gov.br>. Acesso em: 15 fev. 2010.

MATO GROSSO DO SUL. Assembleia Legislativa. Lei Complementar n ${ }^{\circ}$ 87, de 31 de janeiro de 2000. Dispõe sobre o Estatuto do Magistério Estadual de Mato Grosso do Sul e dá outras providências. Campo Grande, 2000a.

MATO GROSSO DO SUL. Lei $\mathrm{n}^{\circ} 2.082$, de 14 de janeiro de 2000. Fixa o piso salarial e o respectivo vencimento-base da categoria funcional de professor do subgrupo Profissionais de Educação Básica e dá outras providências. Diário Oficial do Estado de Mato Grosso do Sul (DIOSUL). Campo Grande, Imprensa Oficial, n.5.182, 17 jan. 2000b. Seção 1, p.6-7.

MATO GROSSO DO SUL. Assembleia Legislativa. Lei Complementar n 97, de 26 de dezembro de 2001. Altera dispositivos da Lei Complementar $n^{\circ} 87$, de 31 de janeiro de 2000, que dispõe sobre o Estatuto dos Profissionais da Educação Básica do Estado de Mato Grosso do Sul. Campo Grande, 2001.

MATO GROSSO DO SUL. Lei n ${ }^{\circ} 3.190$, de 28 de março de 2006. Dispõe sobre a revisão de componentes da remuneração de categorias funcionais integrantes do Plano de Cargos, Empregos e Carreiras do Poder Executivo, institui a categoria funcional que menciona e altera dispositivos da Lei $\mathrm{n}^{\circ} 1.102$ de 10 de outubro de 1990. Diário Oficial do Estado de Mato Grosso do Sul (DIOSUL). Campo Grande, Imprensa Oficial, n.6.698, 28 mar. 2006. Seção 1, p.1-02.

MATO GROSSO DO SUL. Assembleia Legislativa. Lei n 3.368, de 03 de maio de 2007. Cria o Fundo de Manutenção e Desenvolvimento da Educação Básica e de Valorização dos Profissionais da Educação - FUNDEB, e o Conselho Estadual de Acompanhamento e Controle Social do FUNDEB, e dá outras providências. Campo Grande, 2007.

MATO GROSSO DO SUL. Lei $\mathrm{n}^{\circ}$ 3.519, de 15 de maio de 2008. Dispõe sobre o sistema remuneratório, aprova tabelas de vencimento e de subsídio dos servidores das 
categorias funcionais integrantes das carreiras do Plano de Cargos, Empregos e Carreiras do Poder Executivo do Estado, altera dispositivos da Lei n ${ }^{\circ}$ 2.065, de 29 de dezembro de 1999, e dá outras providências.Diário Oficial do Estado de Mato Grosso do Sul (DIOSUL). Campo Grande, Imprensa Oficial, n.7.214, 16 maio 2008. Seção 1, p.9-16.

MATO GROSSO DO SUL. Lei $\mathrm{n}^{\circ}$ 3.795, de 09 de dezembro de 2009. Aprova as tabelas de vencimento-base e de incentivo financeiro dos servidores da categoria funcional da carreira Profissional de Educação Básica e dos cargos de Especialista de Educação e de Professor Leigo. Diário Oficial do Estado de Mato Grosso do Sul (DIOSUL). Campo Grande, Imprensa Oficial, n.7.601, 10 dez. 2009. Seção 1, p.1-03.

OLIVEIRA, R. L. P. Reformas educativas no Brasil na década de 90. In: CATANI, A. F. M.; OLIVEIRA, R. L. P (Orgs.). Reforma educativa em Portugal e no Brasil. Belo Horizonte: Autêntica, 2000. v.1, p.77-94.

PINTO, J. M. de R. Relatório do grupo de trabalho sobre financiamento da educação. Revista Brasileira de Estudos Pedagógicos, Brasília, v.82, n.200/201/202, p.117-136, 2001. PINTO, J. M. de R. Financiamento da educação no Brasil: um balanço do governo FHC (1995-2002). Revista Educação e Sociedade, Campinas, v.23, n.80, set. 2002.

PINTO, J. M. de R. A política recente de fundos para o financiamento da Educação e seus efeitos no pacto federativo. Revista Educação e Sociedade, Campinas, v.28, n.100, out. 2007.

RODRIGUEZ, M. V.; FERNANDES, M. D. E. Conjuntura política e sindicalismo de professores da educação básica (1998-2012). In: GOUVEIA, A. B.; FERRAZ, M. (Orgs.). Educação e conflito: luta sindical docente e novos desafios. Curitiba: Appris, 2012. p.153-194.

SAVIANI, D. Dermeval Saviani analisa o PDE. Informativo Expressão Sindical. SINPRO/ GUARULHOS, 17 set. 2007. Disponível em:

<http://www.simproguarulhos.org.br/entrevista>. Acesso em: 15 fev. 2007.

SENNA, E. Estado, economia e políticas públicas em Mato Grosso do Sul: balanço da década de 80. In: (Org.). Política educacional de Mato Grosso do Sul na trajetória das politicas sociais: análise e diagnóstico (1980-1990). Campo Grande: UFMS, 2000. p.5-48. SINDICATO dos Professores e Servidores do Estado do Ceará - Sindicato Apeoc. Análise comparativa salarial: professores das redes estaduais no Brasil. 2010. Disponível em: <http://www.apeoc.org.br/extra/pesquisa.salarial.apeoc.pdf>. Acesso em: 02 fev. 2013.

Recebido em: 06/04/2013

Aprovado em: 08/11/2013

Contato:

Rua Ourinhos, 318/503

CEP 79005-270

Campo Grande | MS | Brasil 